\title{
Bluetooth embedded digital ammeter with Android app data logging
}

\author{
Chin Fhong Soon ${ }^{1}$, Boon Huei Teng ${ }^{2}$, Kian Sek Tee ${ }^{3}$, Siat Ling Jong ${ }^{4}$, Marlia Morsin ${ }^{5}$, \\ Naszirul A. Rahman \\ ${ }^{1,5}$ Microelectronic and Nanotechnology-Shamsuddin Research Center, Universiti Tun Hussein Onn Malaysia, Malaysia \\ ${ }^{2,3,4}$ Faculty of Electrical and Electronic Engineering, Universiti Tun Hussein Onn Malaysia, Malaysia \\ ${ }^{6}$ NexusLED Green Technology Sdn. Bhd. Parit Sulong Industrial Park, Malaysia
}

\begin{tabular}{l}
\hline \hline Article Info \\
\hline Article history: \\
Received Jul 27, 2019 \\
Revised Oct 28, 2019 \\
Accepted Nov 13, 2019 \\
\hline Keywords: \\
Android app \\
Bluetooth module \\
Digital ammeter \\
Hall-effect sensor \\
Internet of things \\
Mit app inventor \\
\hline
\end{tabular}

\begin{abstract}
Monitoring current supplies to light emitting diode (LED) luminaires is one of the reliability tests performed manually. Bluetooth (HC-05) embedded digital ammeter was proposed to acquire currents of a badge of LED products and hence, quality can be assured. Android App was designed to remotely record the current supplies to the different models of LED products and checking if the current measured is within the allowed range. The current data can be further analysed to control the quality of the LED luminaires produced. The pass and fail-current range can be set in the digital ammeter for alerting abnormal current measured by the operator. Therefore, IOT embedded digital ammeter will help in monitoring data consistency of LED products and improve quality assurance procedure.
\end{abstract}

Copyright $@ 2020$ Institute of Advanced Engineering and Science. All rights reserved.

\section{Corresponding Author:}

Chin Fhong Soon,

Microelectronic and Nanotechnology-Shamsuddin Research Center,

Universiti Tun Hussein Onn Malaysia (UTHM),

Batu Pahat, Johor, Malaysia.

Email: fionasoon@gmail.com

\section{INTRODUCTION}

The fourth industrial revolution (IR) 4.0 and Internet of Things (IOT) is becoming the leading concept in regulating the standard of industry productions [1]. From the first industrial revolution to IR 4.0, digital media and communications system is infused into the previous industrial revolution. Modern technology is intervening the measurement devices in the manufacturing industry. When IOT is introduced in smart factory, it should make the current manufacturing and testing process more efficient. Adoption of IoT is hoped to increase the productivity and reliability of process [2]. IR 4.0 propels the cyber-physical connectivity for devices [3]. Data collected through IOT provides information that we couldn't have perceived without the assistance of IOT.

IoT refers to the connectivity of physical devices that allowing them to exchange data based on a technology that both can communicate. IoT devices are capable to handle remote tasks such as system health monitoring, anonamly monitoring, early intervention of problems, environment monitoring, remote control, service and big data accessing, where all the tasks could be done on internet based wireless technologies [4]. Bluetooth technology is a short-distance wireless technology for replacement of wires connecting devices in radio band of 2.400 to $2.485 \mathrm{GHz}$. Currently, the products in the audio and mobile devices market such as head-set and mouse are popularly embedded with Bluetooth technology. However, this technology is rarely applied in measurement instrumentation such as a bench top Ammeter and Voltmeter for data logging and monitoring. Android framework provides access to the Bluetooth functionalities through the Android Bluetooth application programming interfaces (APIs). 
NexusLED Green Technology Sdn Bhd is a light emitting diode (LED) luminaires manufacturer and supplier in Malaysia. In this industry, operators usually use a digital ammeter and volmeter to test the reliability of their products. In the relilablity department, the operator probes the current of the luminaire using a standard work bench power supply and ammeter. No data recording can be obtained using the existing bench-top power supply which lacks the capability to acquire current or voltage measured or supplied to the device-under test (DUT). Hence, the direct current (DC) data of the LED associated with the quality of product is done individually and manually. If the data of the DC of large quantity of luminaires can be obtained, the manufacturer will have control over the data and quality of the badge of luminaires produced. Therefore, we proposed IOT in improving the digital ammeter to become a more efficient equipment in the industry.

In this paper, the development of a microcontroller based digital ammeter embedded with Bluetooth function is reported. The implementation of wireless modality into an ammeter with the objectives for acquisition of data, monitoring, alerting anomality and data logging for analysis. The connectivity is also enabling remote setting of parameters from an Adroid App to the digital ammeter.

\section{RESEARCH METHOD}

\subsection{The Bluetooth Embedded Digital Ammeter with Half-Duplex Control}

The block diagram for the overall IOT embedded digital ammeter and the Android phone APIs is as shown in Figure 1. Arduino Integrated Design Environment (IDE) was used to program Arduino Atmega 2560 microcontroller which controls input and outputs of the microcontroller in C language. In the program, the microcontroller reads the time and date stamp from the EEPROM of a real time clock (RTC) module. Then, a 10-bit analog to digital contoroller in the microcontroller converts the analog signals send from the ACS 172 dc current sensor to the digital value between 0-1023. The sensor was connected to the DUT to read the current supplies to the DUT. With the digital values, the microcontroller verifies if the current read is within the pass current range. If the current is not within the set limit range, the Red LED will be ignited and vice versa for the Green LED.

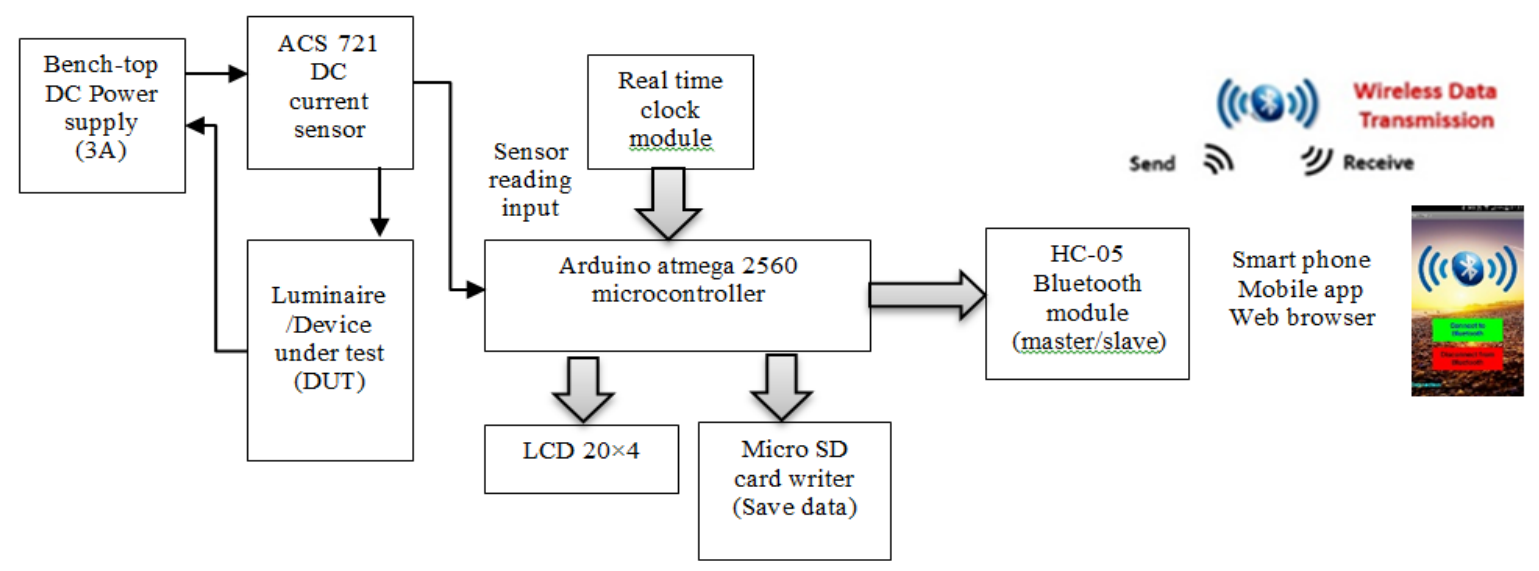

Figure 1. Half duplex Bluetooth embedded digital ammeter transmission system

The data (current, status, time and date) will be updated and displayed on a $20 \times 4$ liquid crystal display (LCD) every second. Data of the current sensed is continuously transmitted to the Android phone via Bluetooth (HC-05) module in half-duplex communication. The microcontroller is always ready to receive the current-pass range (minimum and maximum) values from an android phone. Serial print command was used in the microcontroller to send the DC current data to the Bluetooth for wireless transmission. The android app was designed using MIT inventor software to communicate wirelessly with the Bluetooth module of the digital ammeter. Furthermore, the data can be saved into a microSD card in comma separated value (CSV) format.

\subsection{The Control App Design}

The Android App was used as a remote controller having two main functions: receives and displays current data from the digital ammeter and send the set current-pass range from the Android App to ammeter. The app was designed with two sections in a user interface: The section for displaying the received current 
data and the section with text boxes to enter the current limit information. MIT App inventor 2, an online platform was used to design the interface of the Android App. MIT App inventor is a graphical programming software that requires to connect blocks of program into interlocking program. For initiation of communication, Bluetooth on mobile phone must be first enabled, paired and connected with Bluetooth HC-05 embedded in the digital ammeter. While receiving data, the app checks and determines the number of byte of data available according to the clock as shown in Figure Figure 2(a). When data starts streaming, the app informs the Bluetooth module to receive the current data and display on the displaying section. The app continuously receive data if the incoming data is available. However, if the "Set Current" button is triggered, the Bluetooth module would be switched to the current-pass range setting mode. On the app browser, the user can key in the minimum (upper) and maximum (lower) limit currents into the two text boxes and the MIT App inventor code is as shown in Figure 2(b). After the current range is set and the "Set Current" button is pressed on the app, the app is ready to send both values to the ammeter. The MIT App inventor code for this part is as shown in Figure 2(b).

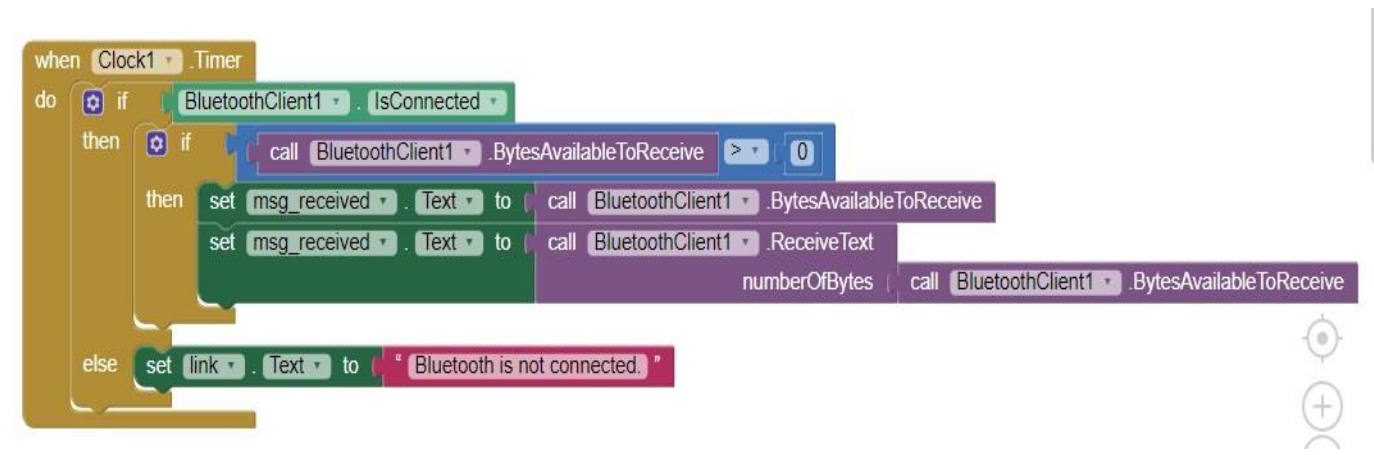

(a)

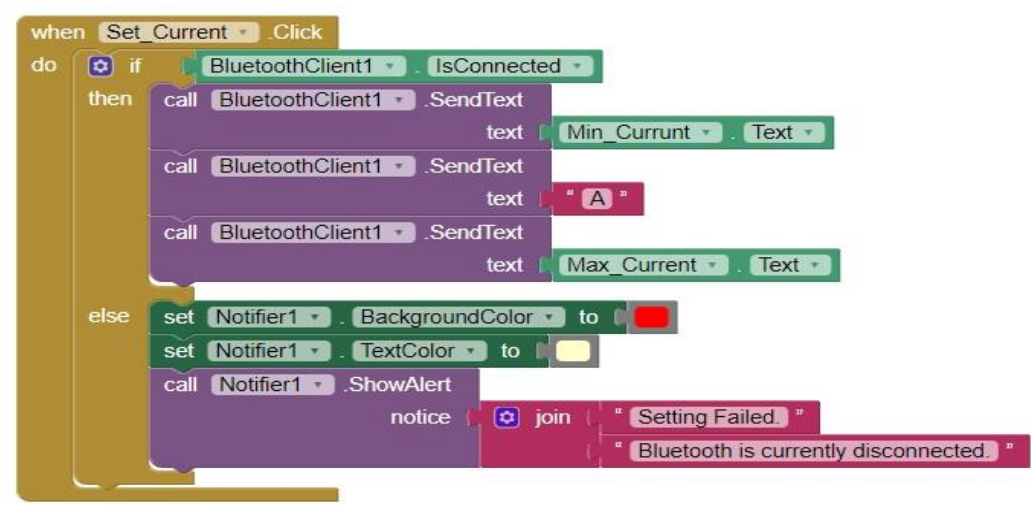

(b)

Figure 2. (a) MIT app inventor program for data receiving, (b) MIT Inventor programming for current-pass range setting

The detailed description of the program flow for the MIT App inventor program is as shown in Figure 3. There are two browser interfaces: The main interface for pairing bluetooh devices and second interface is for the DC current display screen with pass current range text boxes. Instruction of the main interface have four paragraphs. First paragraph, the application will close when back button is pressed. In second paragraph, when the application starts the first screen, it will check whether the Bluetooth on the smartphone is turned on, if the Bluetooth is off, the application will show a notice to tell the user that the Bluetooth is not enabled. Third paragraph, when the "Connect" button is clicked, application will go to the second interface. Fourth paragraph, when "Disconnect" button is clicked, application will call the Bluetooth to disconnect and set the label of connection status to tell the user that Bluetooth is disconnected.

Second interface is the interface for setting current and communication to the bluetooh module. When the second screen is initialized, the application checks whether the Bluetooth is connected as shown in Figure 3 and Figure 5. If the Bluetooth on smartphone is not connected with the HC-05 Bluetooth module, 
the label of the connection status shows "Bluetooth is not connected.", then set the elements of list picker to the address and name of Bluetooth and call the list picker to open. If the Bluetooth is already connected, the connection status will directly show "Bluetooth is connected."

The second part is the selection of bluetooth devices to be connected. When second screen is initialised, the Bluetooth is normally not connected, and the list picker will open to inquire the user to select the Bluetooth to be connected. After the user has chosen the Bluetooth address and name, the application will call the Bluetooth to connect and set the connection status to "Bluetooth is connected". The third part is related to Bluetooth receiving message. For Bluetooth to receive message, it needs a clock signal to control the speed of data receiving. When clock signal is ready, the application will check the Bluetooth connection to ensure the Bluetooth is always connected. Then the application determines whether the Bytes available to receive of the Bluetooth is more than 0, this means that there are messages coming in Figure 2(a). The application will then call the Bluetooth to receive message with streams of bytes continuously. In the fourth part, if there is any error occurs during the operation, the application will call the status link to show the error details and message.

In the fifth part, the application sendS two values to the digital ammeter via Bluetooth $\mathrm{HC}-05$ at the same instance when the "Set Current" is enabled. The two values of minimum and maximum current are the limit set the user at the current text box on the Android App. If both connected strings are send, it can't be recognized. Hence, the function Serial.parseFloat() was applied to read separate strings and changed them into float values. A character 'A' was used as a separation between the two values as shown in Figure 2(b). At the sketch of the Arduino microcontroller, the function Seria.parseFloats() reads in the float numbers of the current values set and ignore any type of characters such as 'A'. Figure 2(a) shows the block program of the MIT App program for getting data from the Bluetooth and Figure 2(b) presents the block program for current-range entering.

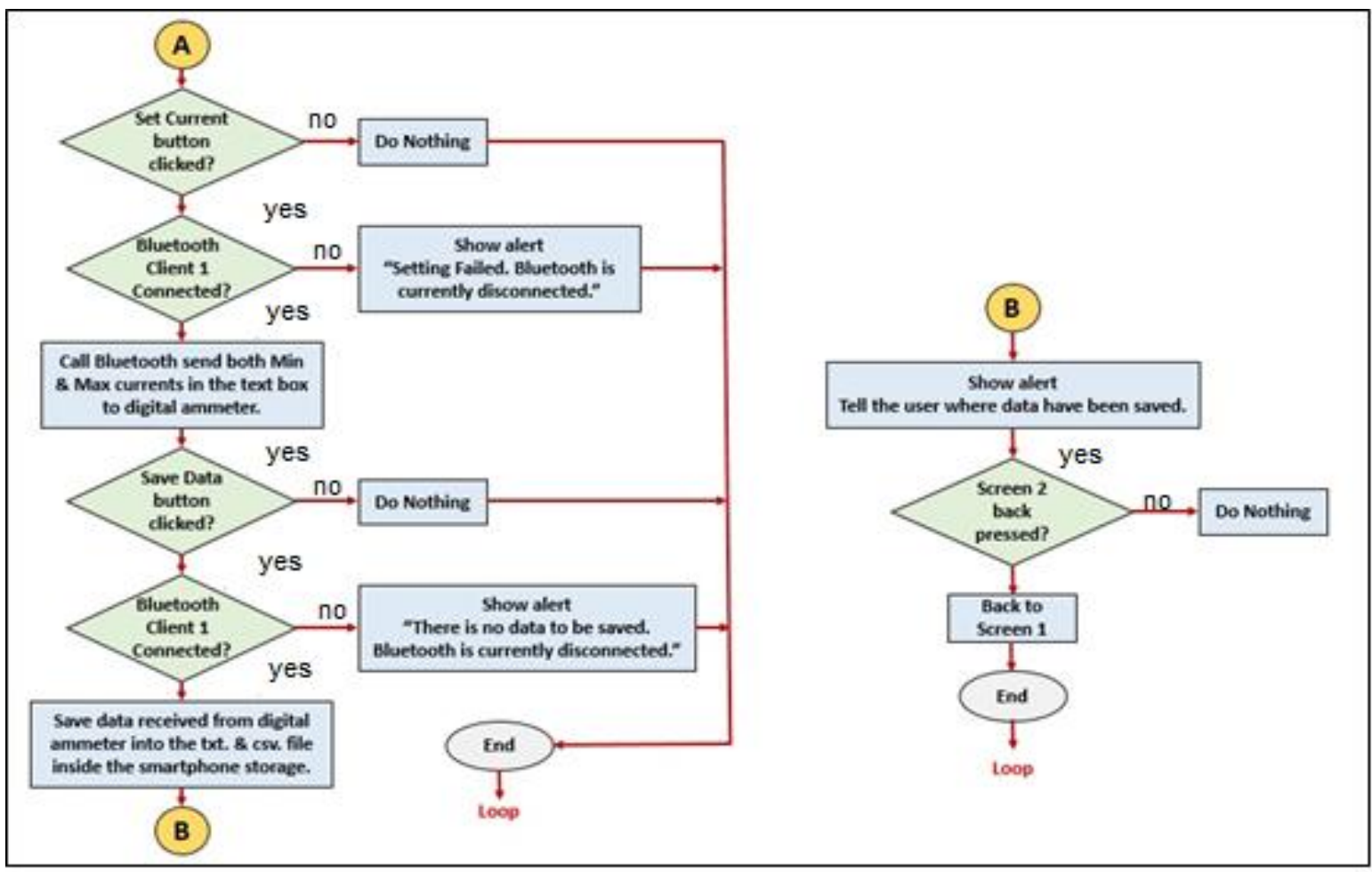

Figure 3. Operation Flow Chart of the Second Screen of the designed Android App

\subsection{Signal Availability Measurement at Different Angles and Distance}

The Bluetooth signal integrity has been determined in an open and obstructed spaces. The signal integrity measurement marked as presence or absence was measured according to the angle of deviation in a fixed diameter as shown in Figure 4, this experiment was carried out in different angles by moving the Android phone away from the digital ammeter at the center and recorded whether the current data is received from the digital ammeter to the Android app. 


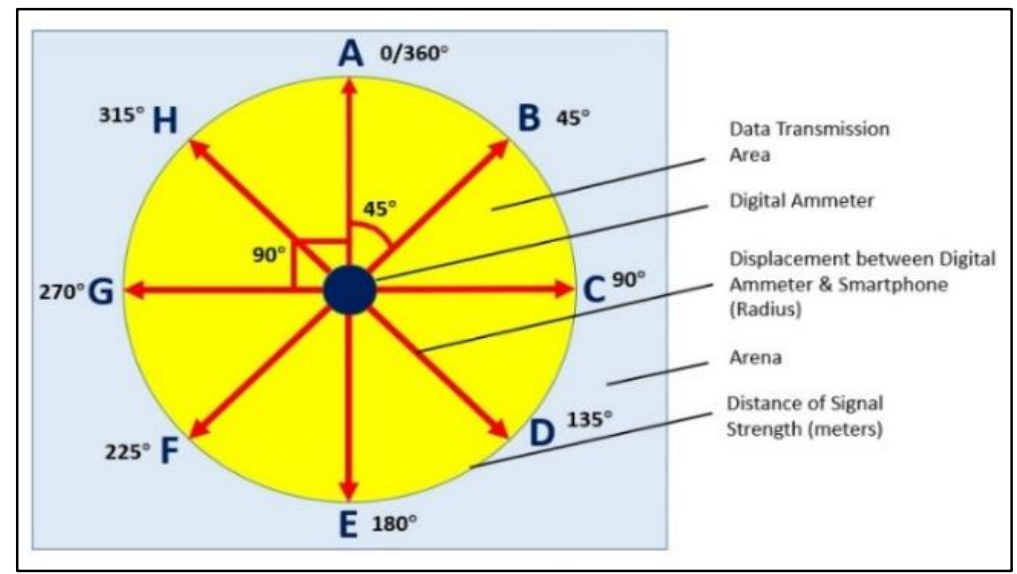

Figure 4. Bluetooth signal availability measurement setup in open space and barricaded area

\section{RESULTS AND ANALYSIS}

The developed digital ammeter embedded with the customised Android App as shown in Figure 5 can measure current between 0.01 to 20A. The Android App consists of two user interface which is the first user interface verifies the success connection between the mobile phone app and the Bluetooth module, and the second user interface is dedicated for current data management. The two buttons on the the first user interface is for connection to the Bluetooth communication and disconnection from the Bluetooth, respectively. The connection button must be first activated before proceeding to the second user interface [5]. The list picker interface provides the selection for Bluetooth device to be connected. Then, the mobile App starts linking with the Bluetooth transmitter with the designated IP address [6, 7].

After the connection is detected and connected, the second user interface starts streaming the incoming data received from the sender Bluetooth module. At the second part of the user interface, the current pass range is displayed and for user to enter the desire current range. A save button is provided for the user to save the current range set for the remote Ammeter. The data received will be saved in the csv file in the memory card of the mobile phone [8]. This work is different from a previous study that applied Wi-Fi for smart LED monitoring which is limited to area with wide are network facility [9].

For success signal transmission, factors such as signal strength, signal lossess, frequency and transmission channels are important with minimum errors. Since every Bluetooth (HC-05) module has its own IP address, even though the operation frequency of Bluetooth device is between $2.4-2.5 \mathrm{GHz}$ [10], Bluetooth will only communicate with the valid IP address which is the channel connected between digital ammeter and mobile phone [11]. Therefore, Bluetooth can hardly interfere each other within the same environment. Figure 6 shows the results for the data transmission distance from ammeter to Android app. The maximum distance for the Bluetooth to transmit and receive data was 7 meters, the transmission was most stable within this range. However, it was noticed that the signal availability in barricaded area is same as in open area. This is uncertain because wireless signal travelled in air instead of solid medium, it can easily be interfered by many environmental factors such as electromagnetic fields. Hence, it is advisable to monitor the current measurement within the same floor of building to avoid lost of data transmission.

The Bluetooth is connected to the microcontroller via the TX and RX pin using the Serial Port Protocol. It can be used as master or slave. Universal Asynchronous Receiver-Transmitter (UART) is the integrated circuit in the Bluetooth module which regulates the data transmission in sequentially [12, 13]. In HC-05, data can be transmitted in two-ways either full-duplex or half-duplex [14]. UART system allows the exchange of a maximum of 20 bytes of data per transmission in bi-direction or more directions [15]. The specification in the datasheet of the HC-05 Bluetooth module states that the transmission range of data can reach up to 100 meters in free space. Unlike what was claimed by the manufacturer of the Bluetooth module, the signal in this study could only reach a maximum distance of 7 meters regardless of obstacles in this experiment. The specification of the HC-05 states that $\mathrm{HC}-05$ can transmit up to $+4 \mathrm{dBm}$ radio frequency transmit power which is equivalent to $4 \mathrm{~mW}$ of power. It seems that $\mathrm{HC}-05$ belongs to the Class 2 bluetooth [16] that could transmit with a range of 10 meters in a typical transmission power of $2.5 \mathrm{~mW}[17,18]$. Bluetooth headsets and headphones are common Class 2 devices. However, transmission range can be significantly impacted by obstacles between the two devices, such as walls that attenuate signals strength. Thus, the transmission distance is influencecd by transmitter power, receiver sensitivity and obstructions in the device's proximity. 


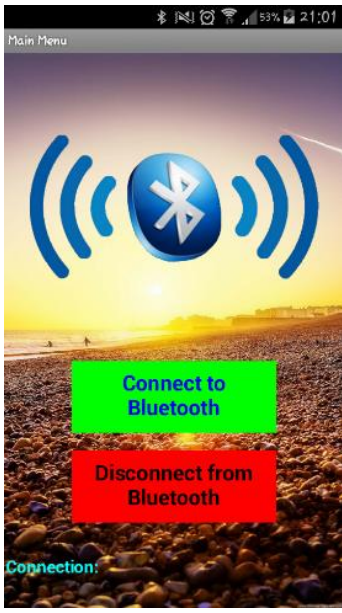

(a)

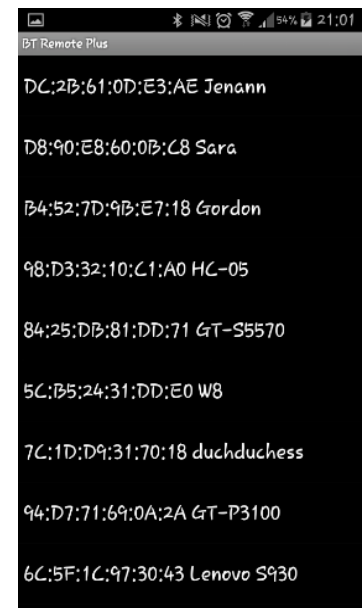

(b)

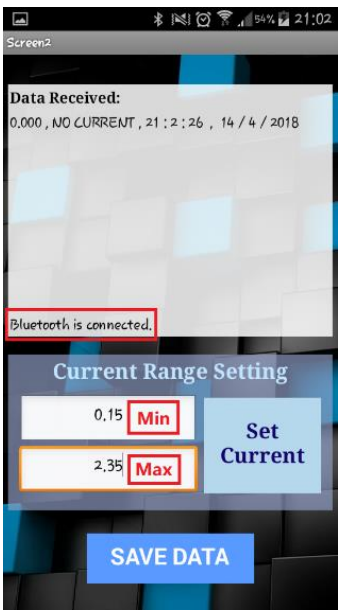

(c)

Figure 5. Android App (a) 1st Interface, (b) List Picker for Bluetooth Device Selection, (c) 2nd Interface

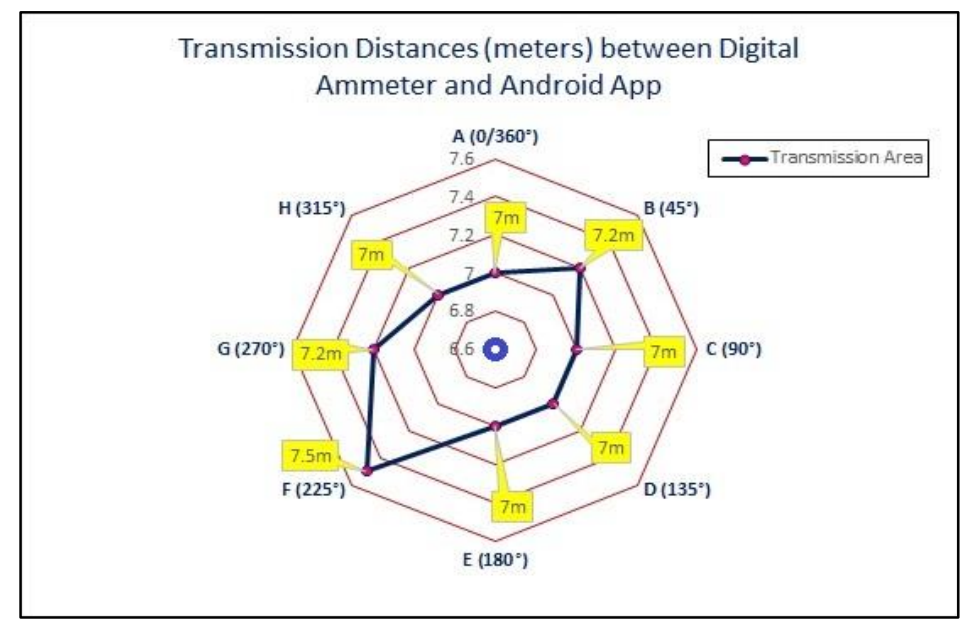

Figure 6. Bluetooth signal transmission distance (in meter) to Android app at different angles

The transmission and reception speed were resonably fast as the baud rate of the Arduino Serial Port is 9600 bit per second (bps) [19, 20]. Therefore, the received data (current, status, time and date) will be immediately displayed on the Android app. However, the Bluetooth transmission can be increased to 38400 bps that the Arduion microcontroller can handle. It means, the transmission speed can be further improved.

However, the ACS 712 hall-effect sensor is sensitive to the surrounding magnetic field [21, 22]. To avoid error, digital ammeter must be kept away from electronics devices which produce high magnetic field. In addition, user should ensure that the digital ammeter is always standing upright to fix its orientation instead of lying down and proper shielding is provided [23]. The data saved in the csv format displays first column with the current value in unit of Ampere; second column is the status of the current measured (No Current/ Pass/ Fail), third column is displayed with the time and the fourth column is for the date. Bluetooth security can be added for protection of data for the ammeter [24, 25]. Smart metering focused more on wireless AC current monitoring but this work on wireless DC ammeter is not reported elsewhere [25].

\section{CONCLUSION}

The hardware and software of a Bluetooth based digital ammeter has been developed with the Android App as the remote monitor. Data of current measurement was transmitted continuously at approximately 1 second of interval to be displayed on an Android App. Prior to data transmission, pairing of the Bluetooth module on device and on mobile phone needs to be established first. Through this system, no 
wire and computer are required for the data acquisition within 7 meters of devices distance and data can be stored in a portable mobile phone memory. The memory is enough to record current data for thousand pieces of LED luminaires under test. Alert system is also available in the ammeter to indicate pass/faile current measured for the DUT. From the data obtained in the phone, current distribution graph can be produced to understand the data distribution for a badge of products. This is an advantage that the existing bench-top ammeter can not provide. The additional feature could benefit the test measurement industry.

\section{ACKNOWLEDGEMENTS}

The authors are grateful to the financial support from "Insentif Kecemerlangan Penyelidikan dan Inovasi 2018”, Vot. No. H378 awarded by Universiti Tun Hussein Onn Malaysia.

\section{REFERENCES}

[1] McCabe, B., "A Short History of the Fourth Industrial Revolution", Retrieved May 13, 2018, from http://www.ioti.com/industrial-iot/short-historyfourth-industrial-revolution.

[2] Albert, M., "7 Things to Know about the Internet of Things and Industry 4.0", Retrieved May 13, 2018, from https://www.mmsonline.com/articles/7-things-to-know-about-the-internet-ofthings-and-industry-40.

[3] Singh, S., "Demystifying industry 4.0 and the industrial internet of things", Retrieved May 13, 2018, from https://yourstory.com/2017/07/demystifying-industry-industrial-internet-of-things.

[4] "The Industrial Internet of Things (IIoT): The business guide to Industrial IoT". (n.d.). Retrieved May 13, 2018, from https://www.i-scoop.eu/internet-of-thingsguide/industrial-internet-things-iiot-saving-costs-innovation.

[5] Alsibai, M.H., Siang, H.M., "A smart driver monitoring system using android application and embedded system", In Proceedings of the 5th IEEE International Conference on Control Systems, Computing and Engineering (ICCSCE 2015), November 2015, 242-247.

[6] Xie, Benjamin X., Shabir I., Abelson H., "Measuring the Usability and Capability of App Inventor to Create Mobile Applications", Proceedings of the 2015 ACM SIGPLAN Conference on Systems, Programming, Languages and Applications: Software for Humanity (SPLASH), 1-9.

[7] Franklyn T., David W., Paul W., "Design of naming features in App Inventor 2", 2014 IEEE Symposium on visual languages and human-centric computing, 1-6.

[8] Mitlohner, J., "Characteristics of Open Data CSV Files", 2016 2nd International Conference on Open and Big Data (OBD), Vienna, 2016, 72-79.

[9] Sung, W.T.; Lin, J.S., "Design and implementation of a smart LED lighting system using a self adaptive weighted data fusion algorithm", Sensors 2013, 13, 16915-16939.

[10] Saha, P. B., et al., "Compact microstrip parallel coupled bandpass filter with a centre frequency of $2.4 \mathrm{GHz}$ suitable for bluetooth and GPS communications", 2015 2nd International Conference on Signal Processing and Integrated Networks (SPIN), Noida, 2015, 650-654.

[11] Dermawan, C., and Sugiura, A., "Wireless IP phone using Bluetooth for ITS application", 2003 IEEE Topical Conference on Wireless Communication Technology, Honolulu, HI, USA, 2003, pp. 204-205.

[12] Shin, M., Park, et al., "Area-efficient digital baseband module for Bluetooth wireless communications", 2002 IEEE International Symposium on Circuits and Systems. Proceedings (Cat. No.02CH37353), Phoenix-Scottsdale, AZ, USA, 2002, V-V.

[13] Preetha, K. G., "A novel solution to the short range bluetooth communication", International Journal on AdHoc Networking Systems (IJANS), Vol. 1, No. 2, 2011, 13-22.

[14] Bhadra B., Vij V. S. and Stevens K. S., "A low power UART design based on asynchronous techniques," 2013 IEEE 56th International Midwest Symposium on Circuits and Systems (MWSCAS), Columbus, OH, 2013, 21-24.

[15] Pratibha S., Dipesh S., Sonu Agrawa, "A Modern Study of Bluetooth Wireless", International Journal of Computer Science, Engineering and Information Technology (IJCSEIT), Vol.1, No.3, 2011, 55-63.

[16] Muhammed Rijah, U.L., Mosharani S., Amuthapriya S., Mufthas M.M.M, Malikberdi Hezretov and Dhishan Dhammearatchi, "Bluetooth Security Analysis and Solution", International Journal of Scientific and Research Publications, Volume 6, Issue 4, 2016, 333-338.

[17] Nateq B.N and Mohammed T., "Bluetooth security threats and solutions: a survey", International Journal of Distributed and Parallel Systems (IJDPS), Vol.3, No.1, 2012, 127-148.

[18] Pravin B., "Bluetooth: Technology for Short-Range Wireless Apps, Industry Report", IEEE Internet Computing, pp. 96-103.

[19] Shawn H., "Serial Communication. Alternating Current (AC) vs. Direct Current (DC)", SparkFun, learn.sparkfun.com/tutorials/serialcommunication/rules-of-serial. 2019.

[20] David, N, A, F.N., Ebuka, F.O., Nzenweaku, S.A. "Design of an Arduino Based Wireless". International Journal of Science Engineering. Research, 7, 2016, pp. 466-469.

[21] Liu H., Wang D., Wang D. F. and Wang D., "Developing a passive DC current sensor," 2016 IEEE Sensors, Orlando, FL, 2016, 1-3.

[22] Mohannad J. M., Alex V. d. B. and Raad F. C., "A smart voltage and current monitoring system for three phase inverters using an android martphone application", Sensors, Vol. 17, No. 872, 1-16. 
[23] Abdul A. M., Md. F. P., Md. K. H, Sapan K. S., Pico-current Measurement Challenges and Remedies: A review, Universal Journal of Engineering Science, Vol. 5, Issue 4, 2017, 57-63.

[24] Jun H., Albazrqaoe W., Xing G., "BlueID: A practical system for Bluetooth device identification," IEEE INFOCOM 2014-IEEE Conference on Computer Communications, Toronto, 2014, 2849-2857.

[25] Piromalis, D., Arvanitis, K., "Sensotube: A scalable hardware design architecture for wireless sensors and actuators networks nodes in the agricultural domain", Sensors, Vol. 16, Issue 1227, 2016, 1-59.

\section{BIOGRAPHIES OF AUTHORS}

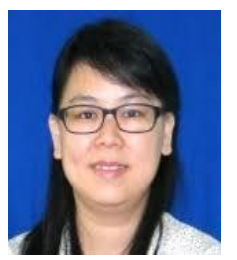

Dr. Chin Fhong Soon is currently an Associate Professor, chartered engineer and the head of Microelectronics and Nanotechnology-Shamsuddin Research Centre (MiNT-SRC), Institute for Integrated Engineering (IIE), Universiti Tun Hussein Onn Malaysia (UTHM). Her current research interests are LORA technology, wireless communication, bio-medical instrumentation and 3D bioprinting.

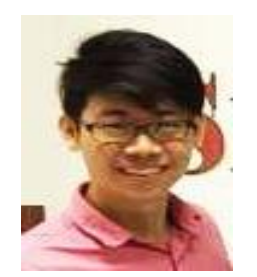

Boon Huei, Teng is a graduate of Universiti Tun Hussein Onn Malayisa who is currently working in Intel Technology Sdn. Bhd. He was graduated with a Bachelor in Electronics Engineering (Honours) in year 2018. His research interest is in wireless communication with microcontrollerr applications. $\mathrm{He}$ has strong command in programming language such as $\mathrm{C} / \mathrm{C}++$ and web development language.

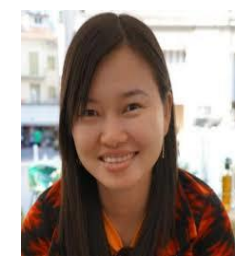

Dr Siat Ling Jong serves as a senior lecturer at the Faculty of Electrical and Electronics Engineering, Universiti Tun Hussein Onn Malaysia (UTHM). Her research interest is in IOT and communication engineering.

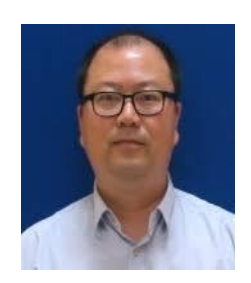

Dr Kian Sek Tee is an associate professor at the Faculty of Electrical and Electronics Engineering, Universiti Tun Hussein Onn Malaysia (UTHM). He has vast experiences in insturmentaiton design.

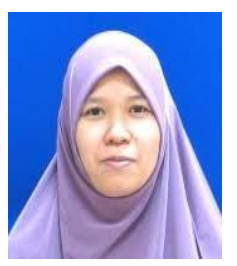

Dr. Marlia is currently a senior lecturer and principle researcher at Microelectronics and Nanotechnology-Shamsuddin Research Centre (MiNT-SRC), Institute for Integrated Engineering (IIE), Universiti Tun Hussein Onn Malaysia (UTHM). Her research interest is in sensor technology.

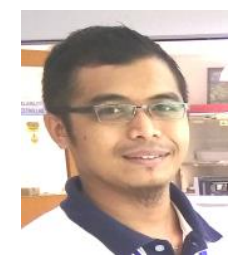

Naszirul A. Rahman is a Quality Reliability Test Engineer at NexusLED Green Technology Sdn. Bhd. He performs reliability test on LED luminaire products according to the IEC and UL standards that include heat point test, burn-in test, ageing test for LED and IP67 test. 